\title{
ARQUEOLOGIA HISTÓRICA - ABORDAGENS
}

\author{
Historical Archaeology - Approaches \\ Diego Antônio Gheno* \\ Neli Teresinha Galarce Machado*
}

\begin{abstract}
RESUMO
Este artigo aborda as potencialidades teóricas e metodológicas da Arqueologia Histórica, destacando como esta subdisciplina passou a ser aplicada em diferentes contextos, relacionada a modelos teóricos amplos, como o histórico-culturalismo, o processualismo e o pós-processualismo. A Arqueologia Histórica, no continente americano, é uma fecunda via de estudo da cultura material proveniente do período moderno. Dessa forma, quando adotamos suas teorias e métodos, geralmente as pesquisas referem-se a materiais industrializados, como metais, louças e recipientes de vidro. A análise central do estudo entoa a relação entre a arqueologia e a história, pois trata-se da materialidade e do cotidiano, gerando uma problematização entre saberes, pois o cotidiano somente será compreendido se houver a relação dos sistemas históricos que contribuam para explicar o funcionamento da civilização material e de seu contexto de estabelecimento, o qual é indissociável do estudo do capitalismo. A definição exata de Arqueologia Histórica constitui uma questão controversa na atualidade científica das ciências humanas e é imprescindível entender o contexto histórico e social, pois assim poderemos incluí-la em uma esfera mais ampla no que tange aos seus preceitos teórico-metodológicos, ou seja, com a Arqueologia. Conceituamos a Arqueologia como o estudo dos grupos humanos, em seus mais diversos aspectos, através da sua cultura material e das formações sociais desaparecidas. No entanto, a área de atuação do arqueólogo pode variar de acordo com o seu objeto de pesquisa. Neste sentido, há no Brasil uma dicotomia relacionada à problemática referenciada: a Arqueologia Pré-Histórica e a Arqueologia Histórica. A Arqueologia Pré-Histórica seria a arqueologia dos grupos humanos sem escrita, enquanto a Arqueologia Histórica trata a cultura material dos grupos humanos com escrita. Considerando ineficiente a divisão das "arqueologias" somente no que tange à escrita, propomos distingui-las através da formação do

\footnotetext{
* Centro Universitário Univates.
} 
Mundo Moderno, que se inicia com a expansão europeia e coincide com a consolidação do sistema capitalista e de uma nova ordem social. Outro aspecto tratado no texto é uma breve revisão sobre pesquisas em perspectiva da Arqueologia Histórica no Brasil, Rio Grande do Sul e na região geopoliticamente conhecida como Vale do Taquari.

Palavras-chave: Arqueologia Histórica; teoria; metodologia; contexto.

\begin{abstract}
This paper discusses the theoretical and methodological potential of Historical Archaeology, highlighting how this subdiscipline has been applied in different contexts, related to wide theoretical models such as historical-culturalism, processualism and pos-processualism. The historical archaeology, in the American continent, is a fruitful way of studying the material culture from the Modern period. Thus, when we adopt their theories and methods, usually the researches refer to industrial materials, like metals, porcelain and glass containers. The central analysis of the study is based on the relation between archaeology and history, because it relates to materiality and everyday life, creating a questioning among knowledge, since the everyday life only will be understood if there is a connection between the historical systems that contribute to explain the operation of material civilization and their establishing context, which is inextricably inked to the study of capitalism. The exact definition of historical archaeology constitutes a controversial issue in current human sciences and it is essential to comprehend the historical and social context, because then we may include it in wider sphere regarding their theoretical and methodological principles. We conceptualize archaeology as the study of human groups, in their various aspects, through their material culture, and based on their disappeared social formations. However, the field archaeologists works may vary according to their research subject. Thus, there is, in Brazil a dicotomy related to the referred issue: the prehistoric archeology and the historical archaeology. The prehistoric archaeology so would be the archaeology of human groups without writing, while the historical archaeology handles with material culture from human groups that write. Considering inefficient the division of "archaeologies" regarding the writing criterion, we propose to distinguish them through the Modern world formation, that begins with the European expansion and coincides with the consolidation of capitalist system and with a new social order. Another aspect discussed in the text is a brief review about researches in historical archaeology perspective in Brazil, state of Rio Grande do Sul and in the area known, geopolitically, as Taquari Valley (Vale do Taquari).
\end{abstract}

Keywords: Historical Archaeology; theory; methodology; context. 


\section{Introdução}

Toda definição acabada é uma espécie de morte, porque, sendo fechada, mata justo a inquietação e curiosidade que nos impulsionam para as coisas que, vivas, palpitam e pulsam (SANTAELLA, 1983, p. 9).

Primeiramente, a Arqueologia Histórica é uma subdisciplina da Arqueologia, portanto, uma ciência com teorias e métodos próprios (FUNARI, 2002; NAJJAR, 2005; SYMANSKI, 2009). Dessa forma, as definições que abordaremos servem para corroborar o estudo de caso ao qual lançamos mão e não para apresentarmos proposições estáticas e acabadas da referida subdisciplina. Se o fizéssemos, seria um erro grave, porque a Arqueologia Histórica ainda está em fase de construção e amadurecimento, principalmente no Brasil (FUNARI, 2005).

Tentar definir uma ciência, ainda mais se tratando da Arqueologia e de uma de suas variantes, a Arqueologia Histórica, é um processo desafiador para este trabalho. Ainda mais quando percebemos o quão divergentes são as abordagens teórico-metodológicas utilizadas por autores que a estudam e que tratam de um mesmo contexto. Conforme Herberts (2009, p. 39),

não há uma única definição para a Arqueologia Histórica que inclua todas as possibilidades de investigação e que seja aceita unanimemente entre todos os arqueólogos. A própria delimitação do campo de estudo e a abrangência da Arqueologia Histórica Brasileira estão em conceituação e discussão, como todo campo de pesquisa em construção.

Apesar de reconhecermos que a definição exata de Arqueologia Histórica constitui uma das questões mais controversas na atualidade, é imprescindível que situemos esta subdisciplina em seu contexto histórico e social, pois somente assim poderemos entendê-la (FUNARI, 1996; 2004). Em se tratando de Arqueologia História, é inevitável incluirmos esta subdisciplina em uma esfera mais ampla no que tange aos seus preceitos teórico-metodológicos, ou seja, com a Arqueologia. Esta relação é indissociável, pois "os marcos teóricos da Arqueologia Histórica são, como não poderia deixar de ser, os marcos teóricos da Arqueologia" (LIMA, 2002, p. 7). 
De uma forma geral, podemos conceituar a Arqueologia como o estudo dos grupos humanos, em seus mais diversos aspectos, através da sua cultura material (NAJJAR, 2005). No entanto, a área de atuação do arqueólogo pode variar de acordo com o seu objeto de pesquisa. Neste sentido, há no Brasil uma dicotomia relacionada à problemática referenciada: a Arqueologia Pré-Histórica e a Arqueologia Histórica (FUNARI, 1998). A partir desta divisão, baseados em Symanski (2009), classificamos a Arqueologia Histórica como uma subdisciplina da Arqueologia, eliminando, é claro, a carga pejorativa que o termo carrega.

A divisão da Arqueologia no Brasil em Pré-Histórica e Histórica, apesar de consolidada, nos conduz a um sentido tradicional destas noções. A Arqueologia Pré-Histórica seria a arqueologia dos grupos humanos sem escrita, enquanto a Arqueologia Histórica seria a arqueologia dos grupos humanos com escrita. Esta classificação indica uma negação da história dos grupos ágrafos, possuindo sua origem em uma antiga visão segregada do passado (LIGHTFOOT apud FUNARI, 1996; THOMASI, 2010). Considerando ineficiente a divisão das "arqueologias" somente no que tange à escrita, propomos distingui-las através da formação do Mundo Moderno (TOCCHETTO, 2004), que se inicia com a expansão europeia e coincide com a consolidação do sistema capitalista e de uma nova ordem social (SENATORE; ZARANKIN, 2002).

No entanto, conforme Funari (1996), esta classificação parece dar conta de apenas uma parte da questão, pois continuidades milenares podem ser tão ou mais importantes que a crescente europeização do globo. Dessa forma, entendemos que a Arqueologia Histórica pode dar conta também dos grupos sem escrita, através da cultura material, estudando a interação entre dominantes e dominados, letrados e iletrados, em diferentes contextos culturais e cronológicos. É justamente através da cultura material que a Arqueologia Histórica vai dar "voz" às pessoas comuns que não são visíveis no registro documental, mas que fazem parte dos processos que envolvem a formação do Mundo Moderno, como, por exemplo, os escravos no Brasil (FUNARI, 1996; NAJJAR, 2005).

Apesar da tradicional divisão da Arqueologia no Brasil, em Pré-Histórica e Histórica, considerar em primeiro plano a questão da grafia, há certa complexidade nesta classificação das "arqueologias". Conforme o parágrafo anterior, onde relacionamos o estudo da Arqueologia Histórica 
com a formação do Mundo Moderno, devemos considerar também aspectos do principal objeto de estudo da Arqueologia nesta divisão já consolidada: a cultura material.

A cultura material pode ser entendida como um conjunto de elementos que representam condutas, gestos e ideias, tanto no sentido material como no simbólico, inseridas nas relações cotidianas. Como elementos formadores, consideramos todos os artefatos, objetos ou utensílios utilizados por grupos humanos no decorrer de sua presença em determinada paisagem (AZEVEDO NETTO; SOUZA, 2010). Além dos elementos já citados, também podem ser incluídas neste rol as diferentes estruturas relacionadas aos grupos humanos (NASCIMENTO, 2009). Problematizando a noção de cultura material, entendemos que ela "tem uma dimensão mais ampla e diversificada, envolvendo todo o segmento físico socialmente integrado" (REDE, 1996, p. 278).

Segundo Lima (2011, p. 21),

a cultura material é [...] produzida para desempenhar um papel ativo [nos sistemas socioculturais], é usada tanto para afirmar identidades quanto para dissimulá-las, para promover mudança social, marcar diferenças sociais, reforçar a dominação e reafirmar resistências, negociar posições, demarcar fronteiras sociais e assim por diante.

Considerando a cultura material como o principal objeto de estudo da Arqueologia, é também através dela que devemos propor uma distinção entre as "arqueologias" no Brasil.

Segundo Orser Jr. (2005, p. 64), "o surgimento das forças de mercado no mundo capitalista tem um significado prático para os pesquisadores da Arqueologia Histórica, pois a grande maioria dos objetos usados pelos americanos pós-colombianos não foi feita por eles mesmos". Apesar de Orser Jr. (2005) estar fazendo referência ao contexto norte-americano, a referida citação pode ser adaptada ao "cenário" nacional.

O pesquisador que trabalha com Arqueologia Histórica pode utilizar uma variedade enorme de fontes em seus estudos, diferentemente do arqueólogo que trabalha com a Pré-História. Najjar (2005) afirma que os artefatos, os documentos escritos, a informação oral e a própria arquitetura podem 
informar ao pesquisador de Arqueologia Histórica sobre as relações entre os ocupantes desses sítios e como eles se relacionavam com a sociedade.

Em relação às fontes utilizadas na Arqueologia Histórica, Orser Jr. (1992) problematiza-as com maior ênfase e em maior número. Segundo este arqueólogo, na Arqueologia Histórica é comum o estudo de artefatos, estruturas, documentos escritos, mapas, pinturas, desenhos, fotos, história e testemunhos orais, além das transformações na paisagem decorrentes das ações dos grupos humanos.

Baseados em Orser Jr. (1992), classificamos os artefatos em Arqueologia Histórica como aqueles itens fabricados e/ou modificados pela ação humana, incluindo louças, garrafas e frascos de vidro, metais e assim por diante. Já as estruturas, entendidas como qualquer evidência de presença humana que não pode ser removida do sítio arqueológico, estariam relacionadas na Arqueologia Histórica a poços, trincheiras, lareiras, fossas sanitárias, casas, fortes e outras edificações. Esta peculiaridade da Arqueologia Histórica, de poder confrontar diversas fontes, também reserva a esta subdisciplina um papel de destaque no estudo dos grupos humanos. Além de dar "voz" aos esquecidos pela História Tradicional (FUNARI, 1996), cabe à Arqueologia Histórica analisar os domínios nos quais o registro documental é falho ou extremamente tendencioso (LIMA, 2002b).

Segundo Funari (2002, p. 107-108),

tem-se buscado mostrar que ela [Arqueologia Histórica] não é uma simples ancila, serva ou auxiliar da documentação escrita e da ciência da História, pois a cultura material pode não só complementar as informações textuais, como fornecer informações de outra forma não disponíveis e até mesmo confrontar-se às fontes escritas.

Durante muito tempo, a Arqueologia foi vista como auxiliar da Antropologia ou da História, mas não nela mesma. Segundo Funari (1998, p. 8), "ela é considerada uma disciplina independente, intimamente relacionada com a História e com outras ciências sociais". Em relação a este embate, Lima (2002a, p. 11-12) afirma que uma disputa entre o caráter antropológico ou histórico da Arqueologia já não faz mais nenhum sentido nos dias atuais, pois "tanto a antropologia tem uma dimensão histórica 
quanto a história tem uma dimensão antropológica, e a arqueologia deve transitar na inserção entre elas". Sendo assim, não devemos considerar a Arqueologia como auxiliar de nenhuma outra disciplina, mas sim como uma área que busca o "diálogo" com diferentes saberes (FUNARI, 1998). É como afirma Lopes (2009, p. 51):

Esta situação suscita debates que exigem, entre os interlocutores, abertura para questionamentos onde não cabe o dogmatismo teórico ainda verificado nas ciências e muito menos o feudalismo científico que fragmenta as áreas do conhecimento tornando-as, apesar de tão próximas, ilustres desconhecidas.

Dessa forma, considerando a Arqueologia e suas variantes como possuidoras de teorias e métodos próprios que permitem conhecer as tensões sociais e a variedade de situações sociais vivenciadas através da cultura material e da troca de conhecimento com outras disciplinas, a importância da Arqueologia situa-se justamente na democratização do passado, fornecendo aberturas para a vida diária do povo e permitindo que se supere a parcialidade das evidências eruditas (FUNARI, 1998; 2002). Conforme Lima (2002a), a força da Arqueologia Histórica reside justamente no estudo das coisas da vida diária aparentemente pouco importantes para um "olhar leigo", mas que estão intimamente associadas a processos sociais mais amplos.

\section{A Arqueologia Histórica e os modelos histórico- cultural, processual e pós-processual}

Como afirmamos anteriormente que a Arqueologia é uma disciplina independente, apesar de ser um campo multi e interdisciplinar (LIMA, 2002), é necessário situarmos as três principais correntes teóricas que são utilizadas nas abordagens arqueológicas: o modelo histórico-cultural, a arqueologia processual e a pós-processual. Primeiramente, para entendermos tais propostas, é necessário considerarmos as continuidades na utilização destes referenciais, muito antes das rupturas que poderiam ser geradas por 
maneiras de pensar tão distintas. Além disso, estes modelos foram e são adotados tanto na Arqueologia Pré-Histórica quanto na Arqueologia Histórica (SYMANSKI, 1996; FUNARI, 2003).

Inicialmente, antes de abordarmos o modelo histórico-cultural, é necessário reconhecermos que ele continua a ser fortemente empregado na Arqueologia (FUNARI, 2003), o que corrobora a afirmação de uma continuidade nesta forma de pensar a cultura material e o sítio arqueológico. Segundo Najjar (2005), até a década de 1960 a histórico-culturalista foi a perspectiva teórica reinante nos trabalhos arqueológicos, voltados exclusivamente a exaustivas descrições de sítios e materiais arqueológicos.

De acordo com Funari (2003, p. 49), o modelo histórico-cultural

[...] parte do pressuposto de que as pessoas compartilham, de forma homogênea, os traços culturais e que as tradições passam de geração em geração. Todos os indivíduos de determinado grupo compartilham as mesmas ideias e a mesma cultura material. [...].

Esse modelo, ainda que tenha sofrido muitas críticas por seus equívocos (generalizações descoladas da realidade), como veremos, continua a ser o mais utilizado em arqueologia, em suas múltiplas variantes e formas.

Apesar das constantes críticas ao histórico-culturalismo, devido à precariedade das análises empregadas em tal modelo, devemos situá-lo como parte de um processo dialético e de amadurecimento da Ciência Arqueológica. Ao arqueólogo, tendo novas possibilidades teórico-metodológicas em mãos e aceitas em ambiente acadêmico, as críticas ao passado são de fácil elaboração. No entanto, antes de desmerecermos o modelo histórico-cultural, devemos reconhecê-lo como importante etapa da construção do pensamento arqueológico. Apesar de estar vinculado a preceitos nacionalistas de unidade cultural, o histórico-culturalismo resultou em um significativo aperfeiçoamento de métodos arqueológicos, como a seriação, estratigrafia, classificação e aumento da compreensão do modo como se vivia no passado (TRIGGER, 2004, p. 190).

No que tange à abordagem histórico-cultural na Arqueologia Histórica, em sua versão empobrecida, Lima (2002a) afirma que, além do caráter pontual, empiricista, descritivo, classificatório e biográfico do 
referido modelo teórico, há uma preferência pelo estudo de estruturas e artefatos remanescentes dos poderes religioso, militar e civil, conferindo à subdisciplina um caráter elitista. Estas características vão de encontro à Arqueologia Histórica praticada por alguns pesquisadores nos Estados Unidos, que buscam atuar em sítios associados a lugares e personagens importantes na ideologia nacional dominante, em detrimento de análises que abarquem a diversidade dos grupos humanos em um mesmo contexto (ORSER JR., 2005).

Considerada por Najjar (2005) como marco na arqueologia moderna, a Arqueologia Processual, ou Nova Arqueologia, surgiu na década de 1960 nos Estados Unidos como alternativa aos pesquisadores que acreditavam serem possíveis análises mais profundas dos grupos com o meio em que viviam. Foi neste período que a Arqueologia foi aproximada à Antropologia, o que acabou gerando os futuros debates entre processualistas e pós-processualistas. Estes últimos defensores de uma Arqueologia relacionada à História (LIMA, 2002a). Um dos pressupostos básicos da Nova Arqueologia é a busca por "elementos universais de comportamento humano, que não se limitariam a uma ou outra sociedade" (FUNARI, 2003, p. 50).

Para tal premissa, ocorreu a utilização de teorias e métodos nas investigações arqueológicas, o que daria ao processualismo um caráter positivista em decorrência de seu rigor científico. Até mesmo recursos estatísticos e matemáticos foram incorporados na Nova Arqueologia com o intuito de dar validade científica às pesquisas (NAJJAR, 2005). Para situarmos a proposta processualista na Arqueologia História, devemos considerar o pressuposto básico desta forma de pensar: o comportamento dos grupos humanos (TRIGGER, 2004).

Como a Arqueologia Histórica na América estuda o Mundo Moderno, o comportamento relacionado aos hábitos de consumo acabou sendo uma determinante nesta linha de pesquisa. De acordo com Symanski (1996, p. 64), um dos principais temas de debate nos trabalhos de orientação processual em Arqueologia Histórica diz respeito ao modo no qual a variabilidade do status social é refletida arqueologicamente. Um pressuposto básico é que o poder de compra do indivíduo estará refletido na qualidade do material encontrado no registro arqueológico.

Apesar de considerarmos a importância da Nova Arqueologia, Lima (2002a) a critica. Segundo esta autora, o processualismo é uma ferramenta 
teórico-metodológica de pouca utilidade na Arqueologia Histórica, pois enaltece em demasia a antropologia e as generalizações. Em contrapartida, é desapegado da História e nega a importância das trajetórias históricas particulares. Trigger (2004) segue esta mesma linha de pensamento, criticando a Nova Arqueologia por esta se proclamar produtora de generalizações objetivas e etnicamente neutras baseadas em um anti-historicismo. Estas características estão, na verdade, fortemente vinculadas a uma forma de validação da ordem vigente no contexto em que surgiu a Nova Arqueologia: os Estados Unidos da década de 1960, racionalmente projetado para atender aos interesses de indivíduos empreendedores que desprezavam a História (TRIGGER, 2004). Apesar das ferozes críticas, Lima (2002a) e Trigger (2004) reconhecem o processualismo como importante etapa na formação do pensamento arqueológico atual, principalmente no que tange à elaboração de minuciosas metodologias e técnicas científicas.

Além disso, pode fornecer esquemas interpretativos aplicáveis a qualquer contexto histórico (FUNARI, 2003). Na década de 1980, surgiu na Europa, em especial na Inglaterra, uma nova forma de pensar e interpretar os dados arqueológicos em contrapartida à Nova Arqueologia: o pós-processualismo.

Segundo Najjar (2005), este pensamento contribuiu para a Arqueologia na medida em que validou a possibilidade de utilização de uma pluralidade de métodos interpretativos em uma mesma pesquisa, o viés simbólico da cultura material e as análises qualitativas ao invés das quantitativas. $\mathrm{O}$ pós-processualismo também é conhecido como contextual, pois se preocupa com o "contexto histórico e social da produção de conhecimento, com a subjetividade e comprometimento do arqueólogo com os grupos sociais" (FUNARI, 2003, p. 51).

Para entendermos melhor o pós-processualismo, recorremos à noção formulada por Tânia Andrade Lima (2002a, p. 9):

Essa reação, que trouxe consigo o retorno ao historicismo e ao particularismo da velha e desprezada História Cultural, valorizando contextos históricos, ideologias e diversidade, voltou-se para a investigação das estruturas subjacentes às expressões culturais, para os significados da cultura material e sua dimensão simbólica, para o indivíduo em lugar do sistema. 
A partir de Lima (2002a), verificamos que o pós-processualismo é uma importante ferramenta para corroborar as pesquisas em Arqueologia que primam por revelar as especificidades de determinado grupo social, tanto em suas relações internas quanto em um contexto mais amplo, e que reconhecem a importância da História e da dinamicidade da cultura material nas relações sociais (FUNARI, 2003).

A partir destes fatores, e reconhecendo que dentro das sociedades há grande variação, o pensamento pós-processualista busca estudar a dinâmica interna das sociedades, das relações de poder, dos conflitos de classe e de gênero dentro de contextos históricos específicos (LIMA, 2002; FUNARI, 2003). Segundo Symanski (1996), os trabalhos de orientação pós-processual aderem a análises profundamente interpretativas da cultura material, embasadas no que existe de mais recente na produção teórica das ciências sociais.

Se nos primórdios no processualismo o "grito de guerra" consistia em afirmar que Arqueologia é Antropologia ou não é nada, no pós-processualismo passou a ser Arqueologia é História Cultural ou não é nada. Esta afirmação visava a um enfrentamento com o processualismo e a uma troca de saberes entre Arqueologia e História, e não simplesmente colocar a Arqueologia dentro da História Cultural (LIMA, 2002a). Aliás, é preciso reconhecer que durante as décadas de 1980 e 1990 os historiadores culturais aproximaram-se muito dos arqueólogos, principalmente no que tange ao estudo da cultura material (BURKE, 2005). Antes deste fato, na obra O processo civilizador, do cientista social Norbert Elias, o autor aborda os significados simbólicos da cultura material, como o garfo e a faca, bem como os comportamentos a ela associados através de diferentes períodos históricos, havendo uma aproximação com a Arqueologia Histórica.

É interessante observarmos que a primeira edição da referida obra foi lançada em 1939. Logicamente, a forma com que Elias (1994) analisa a cultura material difere, em parte, da maneira como os arqueólogos a analisam. Se a história do pensamento arqueológico pode ser resumida em três linhas teórico-metodológicas, Lima (2002a, p. 9) nos dá a ideia do foco de cada uma delas: se a escala de análise apropriada para o histórico-culturalismo foi o sítio e, para o processualismo, a região, para o pós-processualismo passou a ser o indivíduo. Além destas características, temos na arqueologia histórico-cultural uma ênfase em cronologias de culturas, no processualismo em leis gerais de comportamento e no pós-processualismo um viés contextual, simbólico e crítico (ORSER JR., 1992). 
Em suma, as três principais linhas de pensamento arqueológico, os modelos histórico-cultural, processual e pós-processual, devem ser reconhecidas como etapas de um processo dialético de construção dos referenciais teóricos na Arqueologia. Antes das críticas, é preciso considerar que a convivência de teorias divergentes e, às vezes, contraditórias constitui uma salutar característica da arqueologia na atualidade (FUNARI, 2003).

Sendo assim, não podemos simplesmente desmerecer nenhum dos modelos aqui abordados, pois estaríamos cometendo o mesmo erro de alguns processualistas que recusaram a aproximação da Arqueologia com a História.

\section{Arqueologia Histórica na América}

O estudo de Arqueologia Histórica tal qual propomos no presente trabalho, considerando suas premissas teórico-metodológicas, pode ser entendido somente através do contexto que o legitima: o continente americano a partir da formação do Mundo Moderno. Dessa forma, a abordagem adotada nesta pesquisa faz referência à Arqueologia Histórica surgida na América do Norte. Esta relação pode ser entendida através da seguinte definição: o termo "Arqueologia Histórica" tem sido usado, em particular na América do Norte, para referir-se ao estudo de um período histórico específico, o moderno (sensu anglico, i.e. do século XV em diante, DEETZ 1977), em geral nas Américas.

O termo Arqueologia Histórica, com tal definição, não é usado na Europa e na Ásia, já que se entende por históricas diversas arqueologias, como a Clássica e a Egípcia, para mencionar apenas duas delas (FUNARI, 2002, p. 107). A partir de Funari (2002), verificamos que existe uma variedade de "Arqueologias Históricas" aplicáveis em diferentes contextos. Dessa forma, para corroborar o presente estudo, precisamos reconhecer as peculiaridades da Arqueologia Histórica na América. Esta variante da Arqueologia surgiu no final da década de 1930 nos Estados Unidos em oposição à Arqueologia Pré-Histórica, mais como uma auxiliar da História do que como uma Ciência em si mesma (ZANETTINI, 2005). No entanto, precisamos considerar que a Arqueologia Histórica na América, principalmente no que tange aos seus processos atuais de formação, sofreu fortes 
influências do pensamento europeu a partir da década de 1980, como o pós-processualismo.

Podemos afirmar que a Arqueologia Histórica na América surgiu através do estudo de estruturas e artefatos que estavam vinculados a uma classe dominante, como, por exemplo, monumentos e locais relevantes para a construção e validação das grandes narrativas. Ou seja, vinculada a uma História Tradicional e excludente, onde a elite europeia e seus descendentes eram o centro dos estudos (ZANETTINI, 2005). Tratando inicialmente da cultura material dos grupos europeus na América, este ramo da arqueologia expandiu-se com o passar dos anos, englobando o estudo dos diferentes grupos humanos do continente americano a partir do período moderno. Eis que surge a importância da Arqueologia Histórica: o estudo de práticas sociais e grupos humanos excluídos das narrativas históricas dominantes, pelo viés da cultura material. Segundo Najjar (2005), o objetivo geral da Arqueologia Histórica deve ser o de conhecer, através da cultura material, temas que a história não consegue acessar, pois os objetos têm um valor simbólico que nem sempre é percebido e/ou descrito pela história.

Na América do Norte, estas lacunas estão sendo preenchidas principalmente por pesquisadores como Orser Jr. (1992; 2005), que primam por contribuir no estudo de grupos humanos que não pertençam à elite americana. O referido autor é conhecido por promover pesquisas nas diferentes estruturas de fazendas, o que, no caso da América do Norte, permite compreender como funcionava a interação de grupos de diferentes culturas em um mesmo contexto.

Considerando que a Arqueologia Histórica na América estuda o início do período moderno em diante, ou seja, do século XV até os dias atuais, cabe atualmente à Arqueologia Histórica examinar os primórdios dos processos que envolvem a modernidade, como o colonialismo, o capitalismo, a globalização e o eurocentrismo.

Neste sentido, o que demarca o campo operacional da Arqueologia Histórica na América é justamente o colonialismo europeu (FUNARI, 2002; LIMA, 2002a; LIMA, 2008). Este processo deve ser encarado de forma crítica pelo pesquisador, objetivando sempre denunciar a dependência dos mais variados grupos humanos do continente americano à produção material e intelectual dos países centrais. Além disso, para uma compreensão mais consistente deste processo, aos seus agentes deve ser estendido um papel 
ativo nas relações sociais, onde além da dominação há grande espaço para as diferentes culturas se reinventarem e se apropriarem das coisas a seu jeito (CERTEAU, 1994; LIMA, 2002a).

\section{Arqueologia Histórica no Brasil}

As pesquisas em Arqueologia Histórica no Brasil ampliaram-se recentemente, principalmente na década de 1980 (FUNARI, 2004). No entanto, Tânia Andrade Lima (1993) afirma que foi na década de 1960 que a Arqueologia Histórica emergiu no Brasil como prática de pesquisa institucionalizada. Antes do referido marco cronológico, foram realizados trabalhos em sítios históricos na década de 1930, em fortes militares na Bahia e em estruturas remanescentes de possíveis grupos quilombolas no Paraná, na década de 1940, em uma vila espanhola em Paranaguá/PR, e na década de 1950, em uma capela de um colégio jesuíta no Paraná e nas missões de São Nicolau, São Luiz Gonzaga e São Borja no Rio Grande do Sul. É preciso salientar que os trabalhos realizados antes da década de 1960 não foram publicados e/ou ocorreram de forma totalmente assistemática, a não ser o trabalho citado da década de 1940, de autoria de uma arqueóloga norte-americana, que foi publicado na revista American Antiquity (LIMA, 1993).

Quando tratamos de Arqueologia Histórica no Brasil precisamos considerar que somente com o fim da Ditadura Militar, em 1985, se multiplicaram as pesquisas que deram ênfase à diversidade social brasileira, propiciando um salto quantitativo e qualitativo nos estudos em Arqueologia Histórica no Brasil (LIMA, 2008). Como vemos, o período da Ditadura Militar (1964-1985) tirou inclusive a liberdade de se pesquisar a Arqueologia, o que pode ser considerado como um dos fatores que propiciaram certo atraso na adoção de novas linhas teórico-metodológicas por arqueólogos brasileiros. Esta afirmação pode ser corroborada se considerarmos que foi somente no início da década de 1990 que o processualismo passou a ser adotado nos trabalhos de Arqueologia no Brasil (LIMA, 2002a).

No entanto, a questão dos regimes militares como "sufocadores" da liberdade nas pesquisas em Arqueologia não foi um fenômeno isolado 
e tipicamente brasileiro, pois ocorreu em toda a América do Sul. A Arqueologia Histórica, em especial, foi muito prejudicada, pois, o estudo da cultura material histórica foi feito, por muito tempo, até a década de 1980, principalmente por não arqueólogos, em geral arquitetos e historiadores da arte. Os três países (Argentina, Brasil e Uruguai) foram afetados pelo jugo militar no período entre o início da década de 1960 até meados da década de 1980. Enquanto historiadores e outros estudiosos conseguiram, às vezes, evitar a perseguição, já que seu trabalho acadêmico poderia ser levado adiante às suas próprias expensas, os arqueólogos, pela própria natureza do trabalho de campo, não podiam contar com fundos.

Neste contexto, era muito difícil opor-se à linha oficial dos militares (FUNARI, 1998, p. 13). Devemos considerar que a Arqueologia Histórica no Brasil ainda está em fase de amadurecimento, pois, com a Ditadura Militar, houve uma brusca ruptura no que tange à construção da subdisciplina. É por isso que pesquisadores como Funari (1998), Lima (2002a) e Symanski (2009) vêm alertando os arqueólogos que trabalham com o período histórico para que busquem ferramentas que darão suporte a interpretações críticas da cultura material e que não fiquem presos a análises puramente descritivas em suas pesquisas.

Reconhecendo que a Arqueologia Histórica no Brasil precisa "apertar o passo e acertar o compasso se não quiser ficar para trás", como afirma Lima (2002a, p. 19), os arqueólogos que trabalham com esta subdisciplina devem "libertar-se" da versão empobrecida do histórico-culturalismo e contribuir para a efetiva produção de conhecimento em nosso país, levando em conta a dimensão política da Arqueologia Histórica em dar "voz aos esquecidos" e em contribuir através de novas interpretações em contraponto à História Tradicional (SYMANSKI, 2009). Para situarmos a Arqueologia Histórica brasileira no tempo, convencionou-se como marco cronológico de estudos o período posterior a 1.500 d.C., contemplando os sítios construídos a partir da ocupação portuguesa (NAJJAR, 2005). Segundo Herberts (2009, p. 39), este campo de estudo abarca desde o período da chegada dos europeus no continente americano e a ocupação destes territórios, antes habitados estritamente por populações autóctones, para ser povoado e colonizado por outros grupos étnicos estrangeiros, até os dias atuais.

No entanto, devemos ser mais críticos em relação a este processo. A Arqueologia Histórica no Brasil não pode ser tratada somente pelo viés 
da "europeização", pois, conforme já foi mencionado, havia no Brasil, antes da chegada do europeu, culturas milenares que ainda perduram, além das culturas marginalizadas pela História Tradicional introduzidas pelos processos de formação do Mundo Moderno. Dessa forma, a Arqueologia Histórica deve "olhar" para estes grupos e analisar como eles reinventaram seu cotidiano a partir de uma nova realidade, muitas vezes imposta à força.

De acordo com Nascimento (2009), os estudos de Arqueologia Histórica vêm crescendo no Brasil desde as últimas décadas do século passado, onde Arno Kern, Tânia Lima, Pedro Paulo Funari e Paulo Zanettini, na década de 1990, foram os precursores desse novo campo, apesar de adotarem diferentes concepções teóricas e metodológicas. Na década de 1990, foi inaugurada uma nova fase da Arqueologia Histórica no Brasil, refletida em trabalhos que contemplam temas como: gênero, etnicidade, capitalismo e paisagem (NAJJAR, 2005). Atualmente, os estudos em Arqueologia Histórica no Brasil mostram o caráter multidisciplinar da arqueologia como disciplina científica (NAJJAR, 2005). Este caráter multidisciplinar, associado à série de fontes de informação utilizadas em Arqueologia Histórica, como artefatos, estruturas, arquitetura, documentos escritos, informações orais, imagens e alterações na paisagem, confere à subdisciplina um extenso domínio sobre os aspectos cotidianos e a processos histórico-sociais mais amplos (LIMA, 2002a).

\section{Arqueologia Histórica no Rio Grande do Sul}

Apesar de já termos citado que um dos primeiros trabalhos em Arqueologia Histórica no Brasil ocorreu no Estado do Rio Grande do Sul na década de 1950, é preciso salientar que esta escavação ocorreu de forma totalmente assistemática (LIMA, 1993). Os primeiros trabalhos sistemáticos e com uma metodologia definida ocorreram nas décadas de 1960 e 1970 nos quadros do PRONAPA (Programa Nacional de Pesquisas Arqueológicas), na região das Missões Jesuíticas. Estas pesquisas estavam fundamentadas na abordagem teórica do modelo Histórico-Cultural, buscando sequências cronológicas a partir de estudos tipológicos (OLIVEIRA; SYMANSKI, 1999). 
Na década de 1980, as pesquisas em Arqueologia Histórica no Rio Grande do Sul continuaram concentradas na Região das Missões. Os trabalhos deste período foram realizados por pesquisadores com orientações teóricas distintas, o que acarretou uma falta de uniformização metodológica. A maior parte dos trabalhos foi planejada e desenvolvida nos locais dos antigos povoados de São Miguel, São Lourenço, São João, São Luiz e Santo Ângelo, para os quais foram elaborados projetos específicos (OLIVEIRA; SYMANSKI, 1999; ARQUEOLOGIA HISTÓRICA..., 2011).

A década de 1990 no Rio Grande do Sul inaugurou, nas premissas da Arqueologia Histórica, a preocupação com sítios domésticos, localizados em áreas urbanas e rurais, bem como o estudo de lixeiras coletivas. Estas pesquisas se voltaram para a análise de objetos que compunham o cotidiano de agentes sociais no contexto do século XIX, fundamentadas no processualismo e no pós-processualismo (SYMANSKI, 1996; OLIVEIRA; SYMANSKI, 1999).

Neste período, Tocchetto (2004) afirma que um dos primeiros trabalhos foi realizado no ano de 1994 na parte frontal de um Solar em Porto Alegre. Como publicação de referência da década de 1990, Tocchetto (2004) destaca a dissertação de mestrado de Luís Cláudio Pereira Symanski (1996), que incentivou e tornou possíveis as pesquisas em unidades domésticas. Neste período, houve um crescimento nas publicações e discussões sobre Arqueologia Histórica em diferentes centros de pesquisa do Rio Grande do Sul, como o CEPA (Centro de Ensino e Pesquisas Arqueológicas) da UNISC (Universidade de Santa Cruz do Sul).

A Arqueologia Histórica na década de 2000, no Rio Grande do Sul, foi caracterizada pela continuidade dos trabalhos gerados nos anos 1990, através de análises baseadas no processualismo e no pós-processualismo, como a tese de doutorado de Tocchetto (2004). No entanto, verificamos também neste período as permanências do modelo Histórico-Cultural, como o artigo de Ribeiro, Pestana, Fonseca e Weska (2006). A maioria dos trabalhos em Arqueologia Histórica da década 2000 no Rio Grande do Sul, como teses de doutorado e dissertações de mestrado, concentrou-se na PUCRS (Pontifícia Universidade Católica do Rio Grande do Sul), em movimento que estava ocorrendo desde fins dos anos 1990. 


\section{Arqueologia Histórica no Vale do Taquari}

As pesquisas em Arqueologia Histórica no Vale do Taquari/RS, região geopolítica onde se centra o presente estudo, vêm sendo realizadas pelo Setor de Arqueologia do Centro Universitário Univates há cerca de dez anos. Até o presente momento, as publicações em Arqueologia Histórica no Vale do Taquari/RS estão embasadas nas premissas do patrimônio cultural (MACHADO; LOPES, 2008; MACHADO; LOPES; GHENO, 2009). No artigo intitulado "O patrimônio cultural sob as lentes da Arqueologia Histórica - colonização e imigração no Vale do Taquari/RS", de autoria de Neli T. G. Machado e Sérgio Nunes Lopes, a Arqueologia Histórica é utilizada para denunciar as políticas públicas escassas na referida região em relação à preservação patrimonial, bem como para expor o grande potencial que $o$ Vale do Taquari possui no que tange à implantação de políticas relacionadas ao turismo em estruturas remanescentes de grupos provenientes dos processos de colonização e imigração europeia. Esta premissa é exposta com a finalidade de preservação destes bens, que propiciam uma relação íntima com a identidade dos grupos que habitam o Vale do Taquari.

Neste artigo, também é citada a estrutura arquitetônica onde os recipientes de vidro analisados no presente estudo foram coletados: a Casa Comercial de Arnaldo Fensterseifer. Outra publicação com propósitos semelhantes à anterior é "Arqueologia Histórica e a problemática do patrimônio: discussões acerca da preservação, turismo e educação patrimonial no Vale do Taquari - Rio Grande do Sul", de autoria de Neli T. G. Machado, Sérgio Nunes Lopes e Diego Antônio Gheno. O referido artigo objetiva tratar da pluralidade de interpretações capazes de referenciar vários momentos do cotidiano humano através da cultura material, sob a ótica do Patrimônio Histórico-Cultural e da Arqueologia Histórica. Além disso, o enfoque arqueológico como fonte potencial para confrontar possíveis distorções construídas pela História Tradicional também é elencado neste artigo.

A partir desta breve revisão bibliográfica, percebemos que no Vale do Taquari ainda não foram publicados trabalhos em Arqueologia Histórica que primam por analisar artefatos em um estudo de caso. Sendo assim, o presente trabalho visa preencher, em parte, esta lacuna, bem como contribuir modestamente para a literatura arqueológica brasileira em um estudo sobre recipientes de vidro provenientes de uma casa comercial que "vivenciou" boa parte do breve século XX. 


\section{Considerações finais}

Verificamos que a Arqueologia Histórica é uma subdisciplina da Arqueologia que, na América, estuda o período Moderno. Em relação ao contexto nacional, a Arqueologia Histórica ainda está em processo de construção como ciência. No entanto, este fato não tira da referida subdisciplina suas fecundas vias de análise e interpretação da cultura material, que pode ser relacionada a inúmeras fontes. Além disso, através da cultura material, os estudos em Arqueologia Histórica podem trazer à tona grupos humanos e processos histórico-sociais que não foram tratados nos documentos oficiais.

Discutimos os marcos teóricos da Arqueologia Histórica: o histórico-culturalismo, o processualismo e o pós-processualismo. Procuramos ressaltar as contribuições destas teorias para a construção da Ciência Arqueológica, antes das críticas ferrenhas que são atribuídas a cada uma delas. É importante não nos orientarmos por nenhum modelo teórico específico da Arqueologia, pois acreditamos que todos surgiram através de um processo dialético, complementando-se ao final.

\section{Referências}

ARQUEOLOGIA HISTÓRICA MISSIONEIRA. Programa de Pesquisas Interdisciplinares da Região Platina Oriental (PROPRATA). 2011. Disponível em: $<\mathrm{http}: / /$ www.proprata.com/arqueologia-historica-missioneira> . Acesso em: 31/10/2011.

AZEVEDO NETTO, Carlos Xavier de; SOUZA, Amilton Justo de. A importância da cultura material e da Arqueologia na construção da História. História Unisinos, São Leopoldo, v. 14, n. 1, p. 62-76, jan./abr. 2010. Disponível em: <http:// www.unisinos.br/publicacoes_cientificas /images/stories/pdfs_historia/vol14n1/ art08_netto_e_souza.pdf>. Acesso em: 29/08/2011.

BRAUDEL, Fernand. Civilização material, economia e capitalismo: séculos XV-XVIII. São Paulo: Martins Fontes, 1996.

BURKE, Peter. História e teoria social. São Paulo: UNESP, 2002. . O que é história cultural? Rio de Janeiro: Jorge Zahar Ed., 2005. 
CERTEAU, Michel de. A invenção do cotidiano: 1 . Artes de fazer. Petrópolis, RJ: Vozes, 1994.

; GIARD, Luce; MAYOL, Pierre. A invenção do cotidiano: 2. Morar, cozinhar. Petrópolis, RJ: Vozes, 1996.

DEETZ, James. In Small Things Forgotten: The Archaeology of Early American Life. Nova York: Anchor Press, 1977.

ELIAS, Norbert. O processo civilizador. Rio de Janeiro: Jorge Zahar Ed., 1994.

FREITAS, Luciana S. Cultura material, prática arqueológica e gênero: um estudo de caso. In: FUNARI, Pedro Paulo Abreu (Org.). Arqueologia histórica e cultura material. Campinas, SP: UNICAMP, Instituto de Filosofia e Ciências Humanas, 1998. p. 275-317.

FUNARI, Pedro Paulo A. O amadurecimento de uma Arqueologia Histórica Mundial. Revista de História, São Paulo, n. 135, p. 163-168, dez. 1996. Disponível em: $<$ http://www.revistasusp.sibi.usp.br/scielo.php?script=sci_arttext\&pid=S0034$-83091996000200010 \& \operatorname{lng}=\mathrm{PT} \& n r m=\mathrm{iso}>$. Acesso em: 13/08/2011.

. Arqueologia, História e Arqueologia Histórica no contexto sul-americano. In:__ (Org.). Arqueologia Histórica e cultura material. Campinas, SP: UNICAMP, Instituto de Filosofia e Ciências Humanas, 1998. p. 7-34.

. A arqueologia histórica em uma perspectiva mundial. In: ZARANKIN, Andrés; SENATORE, María Ximena (Orgs.). Arqueologia da sociedade moderna na América do Sul. Buenos Aires: Ediciones Del Trindade, 2002. p. 107-115.

. Arqueologia. São Paulo: Contexto, 2003.

Teorias e métodos na arqueologia contemporânea: o contexto da arqueologia histórica. Mneme Revista de Humanidades, Caicó, v. 6, n. 13, p. 1-5, dez. 2004. Disponível em: <http://www.cerescaico.ufrn.br/mneme/pdf/mneme13/124.pdf>. Acesso em: 21/08/2011.

; CARVALHO, Aline Vieira de. Arqueologia de gênero e diversidade no contexto brasileiro. In: MORALES, Walter Fagundes; MOI, Flávia Prado (Orgs.). Cenários regionais em arqueologia brasileira. São Paulo: Annablume; Porto Seguro, BA: Acervo, 2009. p. 261-277.

HERBERTS, Ana Lúcia. Arqueologia do caminho das tropas: estudo das estruturas viárias remanescentes entre os rios Pelotas e Canoas, SC. 2009. 538 f. Tese (Doutorado) - Pontifícia Universidade Católica do Rio Grande do Sul, Programa de Pós-Graduação em História, 2009.

LIMA, Leilane Patrícia de. Contribuição para a arqueologia histórica em Angra dos Reis: as fortificações em Ponta Leste - um estudo de caso. 2008. 228 f. Dissertação (Mestrado em Arqueologia) - Universidade de São Paulo, São Paulo, 2008. 
LIMA, Tania Andrade. Arqueologia Histórica no Brasil: um balanço bibliográfico (1960-1991). Anais do Museu Paulista, São Paulo, v. 1, n. 1, p. 225-262, 1993. Disponível em: <http://www.scielo.br/scielo.php?scipt-sci_arttext\&pib=s0101-47141993000100015\&Ing=en \&nrm=iso>. Acesso em: 22/09/2011.

. Humores e odores: ordem corporal e ordem social no Rio de Janeiro, século XIX. História, Ciência, Saúde - Manguinhos, Rio de Janeiro, v. 2, n. 3, p. 44-96, fev. 1996. Disponível em: <http://www.scielo.br/scielo.php?script=sci arrtext\&pid=S0104-59 701996000400004\&lng=en\&nrm=iso $>$. Acesso em: 30/09/2011.

. Os marcos teóricos da arqueologia histórica, suas possibilidades e limites. Estudos Ibero-Americanos, Porto Alegre, v. 28, n. 2, p. 7-23, $2002 \mathrm{a}$.

. O papel da arqueologia histórica no mundo globalizado. In: ZARANKIN, Andrés; SENATORE, María Ximena (Orgs.). Arqueologia da sociedade moderna na América do Sul. Buenos Aires: Ediciones Del Trindade, 2002b. p. 117-127.

- Tecnologia demais, comportamento de menos: o olhar da arqueologia sobre vidros históricos. Canindé, Xingó, n. 2, p. 283-290, dez. 2002c. Disponível em: <http://www.max.org.br/biblioteca/Revista/Caninde-02/P283-290TecnologiaDemias.pdf>. Acesso em: 19/09/2011.

- Cultura material: a dimensão concreta das relações sociais. Boletim do Museu Paraense Emílio Goeldi. Ciências Humanas, v. 6, n. 1, p. 11-23, jan./abr. 2011. Disponível em: <http://www.scielo.br/pdf/bgoeldi/v6n1/a02v6n1.pdf >. Acesso em: 08/09/2011.

LOPES, Sérgio Nunes. O patrimônio histórico cultural e a representação simbólica: uma reflexão sobre os limites da História e o protagonismo dos historiadores. 2009. 85 f. Monografia (Graduação) - Curso de História, Centro Universitário Univates, Lajeado, 2009.

MACHADO, Neli Teresinha Galarce. Entre guardas e casarões: um pouco da história do interior do RS - uma perspectiva arqueológica. 2004. 255 f. Tese (Doutorado em Arqueologia) - Universidade de São Paulo, São Paulo, 2004.

; LOPES, Sérgio Nunes. O patrimônio cultural sob as lentes da arqueologia histórica: colonização e imigração no Vale do Taquari/RS. Estudo \& Debate, Lajeado, v. 15, n. 2, p. 51-70, 2008.

;

; GHENO, Diego Antônio. Arqueologia Histórica e a problemática do patrimônio: discussões acerca da preservação, turismo e educação patrimonial no Vale do Taquari - Rio Grande do Sul. História, São Paulo, v. 28, n. 1, p. 575587, 2009. Disponível em: <http://www.scielo.br/pdf/his/v28n1/20.pdf>. Acesso em: 11/08/2011. 
MOTTA, Letícia de Barros. A tralha doméstica e o processo de urbanização de Porto Seguro. 1998. 164 f. Dissertação (Mestrado em Arqueologia) - Universidade de São Paulo, São Paulo, 1998.

NASCIMENTO, Cláudia Bibas do. Múltiplos olhares sobre a presença negra na Lapa - Paraná: história e arqueologia (séculos XIX e XX). 2009. 237 f. Dissertação (Mestrado em História) - Pontifícia Universidade Católica do Rio Grande do Sul, Porto Alegre, 2009.

NAJJAR, Rosana. Arqueologia histórica: manual. Brasília: IPHAN, 2005.

OLIVEIRA, Lizete Dias de; SYMANSKI, Luís Cláudio de. Arqueologia Histórica no Sul do Brasil: um breve panorama. Revista do CEPA, Santa Cruz do Sul, v. 23, n. 29, p. 259-261, jan./jun. 1999.

ORSER Jr., Charles. Introdução à Arqueologia Histórica. Belo Horizonte: Oficina de Livros, 1992.

. O desafio da raça para a arqueologia histórica americana. In: FUNARI, Pedro Paulo Abreu; ORSER Jr., Charles; SCHIAVETTO, Solange Nunes de Oliveira (Orgs.). Identidades, discurso e poder: estudos da arqueologia contemporânea. São Paulo: Annablume; Fapesp, 2005. p. 59-75.

REDE, Marcelo. História a partir das coisas: tendências recentes nos estudos de cultura material. Anais do Museu Paulista, São Paulo, v. 4, n. 1, p. 265-282, jan./dez. 1996. Disponível em: <http://www.scielo.br/scielo.php?script=sci arttext\&pid=S0101-4714199600 0100018\&lng=en\&nrm=iso $>$. Acesso em: 31/102011.

RIBEIRO, Pedro Augusto Mentz; PESTANA, Marlon Borges; FONSECA, Rodrigo Germano; WESKA, Tatiana Farias. Escavações arqueológicas na Igreja Nossa Senhora da Conceição, Rio Grande, Rio Grande do Sul, Brasil. Biblos, Rio Grande, v. 18, p. 15-45, 2006. Disponível em: <http:/www.seer.furg.br/ojs/index.php/biblos/ article/viewFile/75/240>. Acesso em: 31/10/2011.

SANTAELLA, Lúcia. O que é semiótica. São Paulo: Brasiliense, 1983.

SENATORE, María Ximena; ZARANKIN, Andrés. Leituras da sociedade moderna: cultura material, discursos e práticas. In: ZARANKIN, Andrés; SENATORE, María Ximena (Orgs.). Arqueologia da sociedade moderna na América do Sul. Buenos Aires: Ediciones Del Trindade, 2002. p. 5-18.

SOUZA, Ana Cristina de. Fábrica de pólvora e Vila Inhomirim: aspectos de dominação e resistência na paisagem em espaços domésticos (século XIX). 1998. 255 f. Dissertação (Mestrado em Arqueologia) - Universidade de São Paulo, São Paulo, 1998. 
SYMANSKI, Luís Cláudio P. A louça na pesquisa arqueológica: análises e interpretações processuais e pós-processuais. Revista do CEPA, Santa Cruz do Sul, v. 20, n. 23, p. 59-76, mar. 1996.

. Grupos domésticos e comportamento de consumo em Porto Alegre no século XIX: o Solar Lopo Gonçalves. 1997. 232 f. Dissertação (Mestrado em História) - Pontifícia Universidade Católica do Rio Grande do Sul, Porto Alegre, 1997.

. Bebidas, panaceias, garrafas e copos: a amostra de vidros do Solar Lopo Gonçalves. Revista da Sociedade de Arqueologia Brasileira, n. 11, p. 71-86, 1998. Disponível em: <http://api.ning.com/files/Inj3mLWD8ghC401CQPEyOUO2BHeQW8 NBUjrnDWGF4hc68yEobBcIh90cZ*GI6QDlyXj4TUNcpohHnDOY4Dwtq GWpxsCCY9xq/SymanskiBebidasepanacias.pdf $>$. Acesso em: 28/072011.

. As práticas de deposição de refugo de uma unidade doméstica oitocentista: o Solar Lopo Gonçalves. In: CONGRESSO DA SOCIEDADE DE ARQUEOLOGIA BRASILEIRA, 9., 2000. Rio de Janeiro. Anais... Rio de Janeiro. (CD-ROM).

. Louças e autoexpressão em regiões centrais, adjacentes e periféricas do Brasil. In: ZARANKIN, Andrés; SENATORE, María Ximena (Orgs.). Arqueologia da sociedade moderna na América do Sul. Buenos Aires: Ediciones Del Trindade, 2002. p. 31-62.

. Arqueologia histórica no Brasil: uma revisão dos últimos vinte anos. In: MORALES, Walter Fagundes; MOI, Flávia Prado (Orgs.). Cenários regionais em arqueologia brasileira. São Paulo: Annablume; Porto Seguro, BA: Acervo, 2009. p. 279-310.

THOMASI, D. I. Arqueologia Histórica: os metais da Estância Velha do Jarau. Santa Maria: Editora UFSM, 2010.

TOCCHETTO, Fernanda. Fica dentro ou joga fora? Sobre práticas cotidianas em unidades domésticas na Porto Alegre oitocentista. 2004. $334 \mathrm{f}$. Tese (Doutorado em História) - Pontifícia Universidade Católica do Rio Grande do Sul, Porto Alegre, 2004.

TRIGGER, Bruce G. História do pensamento arqueológico. São Paulo: Odysseus Editora, 2004.

ZANETTINI, Paulo Eduardo. Maloqueiros e seus palácios de barro: o cotidiano doméstico na casa bandeirista. 2005. 424 f. Tese (Doutorado em Arqueologia) Universidade de São Paulo, São Paulo, 2005. Disponível em: <http://www.teses. usp.br/teses/disponiveis/71/71131/tde-04082006-170833/pt-br.php>. Acesso em: 21/09/2011.

Recebido em março de 2012. Aprovado em abril de 2012. 